\title{
Treatment of victims of trauma
}

\author{
Gwen Adshead \& Scott Ferris
}

\begin{abstract}
Not all traumatic events cause post-traumatic stress disorder (PTSD), and people develop PTSD symptoms after events that do not seem to be overwhelmingly traumatic. In order to direct services appropriately, there is a need to distinguish time-limited post-traumatic symptoms and acute stress reactions (that may improve spontaneously without treatment or respond to discrete interventions) from PTSD, with its potentially more chronic pathway and possible long-term effects on the personality. In this article, we describe acute and chronic stress disorders and evidence about the most effective treatments.
\end{abstract}

This is an update of a paper originally published 7 years ago (Adshead, 2000). Since then there has been increased interest in post-traumatic stress disorder (PTSD). As the world appears to enter a more uncertain period, attention is being paid to the psychological aftermath of terrorism and natural disasters. However, as the language of PTSD has entered the general lexicon, there is a danger of dilution of the meaning of the term and symptoms. Following the terrorist attack in New York on 11 September 2001, probable PTSD was reported in $7.5 \%$ of New Yorkers, many of whom had no direct involvement in the attacks (Galea et al, 2003).

\section{Prevalence of PTSD}

The prevalence of PTSD within a community will depend to some extent on the prevalence of traumatic events in the life of that community. The National Comorbidity Survey in the USA found the estimated lifetime prevalence of PTSD among adult Americans to be $8 \%$, with women (10\%) twice as likely as men (5\%) to have PTSD at some point in their lives (Kessler et al, 1995). However, this represents only a small portion of those who have experienced at least one traumatic event: $60 \%$ of men and $51 \%$ of women reported at least one traumatic event. The most frequently reported traumas were witnessing someone being badly injured or killed, being involved in a natural disaster or lifethreatening accident, and combat exposure. In this National Comorbidity Survey (which presents the largest data-set and longest follow-up, albeit with retrospective assessments), the rate of PTSD declined at a relatively constant rate over 12 months, with a more gradual decline over 6 years.

Using DSM-IV criteria in a population from Munich, Perkonigg et al (2000) found a much lower lifetime incidence of traumatic events: $25 \%$ in men and $18 \%$ in women. The current rate of PTSD was $1 \%$ in males and $2 \%$ in females. However, in parts of the world where there have been recent conflicts the rates of PTSD can be as high as $38 \%$. These data suggest that it is important to consider context when discussing the prevalence of PTSD in the community, since not all 'communities' are the same.

\section{Normal responses to trauma}

There is clearly nothing abnormal about feeling bad when bad things happen. It is equally clear that acute psychological stress reactions, however normal, are extremely distressing and uncomfortable. The best analogy is that of the fractured limb: the pain is entirely normal but may be treated none the less. DSM-IV (American Psychiatric Association, 1994) and ICD-10 (World Health Organization, 1992) recognise acute stress reactions as diagnostic entities. The features of normal stress reactions are described in Box 1, and DSM-IV criteria for PTSD and acute stress disorder are summarised in Table 1. It appears that most people who survive a traumatic event will make a spontaneous, if painful recovery. Only a minority will develop PTSD and related disorders (about 25-40\%; Green, 1993). However, the unpleasantness of normal acute stress reactions

Gwen Adshead is Consultant Forensic Psychotherapist at Broadmoor Hospital (Dadd Centre, Crowthorne, Berkshire RG45 7EG, UK. Email: gwen.adshead@wlmht.nhs.uk). Her research interests include psychiatric ethics, moral reasoning in psychiatry and attachment histories in abusive parents. Scott Ferris is Specialist Registrar in Psychotherapy at Forest House, Walthamstow, London and was previously Specialist Registrar in Forensic Psychiatry working in the trauma service at St George's Hospital, London. His other research interests include attachment and offence representations. 


\section{Box 1 Normal stress reactions after trauma}

\section{Short-term effects}

- Anticipation phase (often not present): anticipatory anxiety/fear

- Immediate shock, numbness, disbelief

- Acute distress

- Dissociation and denial

- Short-term (1-6 weeks) high levels of arousal

- Intrusive phenomena: thoughts, flashbacks, nightmares

- Poor concentration

- Disturbed sleep, appetite, libido

- Irritability

- Persistent fear and anxiety, especially when reminded of trauma, leading to avoidance behaviour

Long-term effects

- Long-term (6 weeks to 6 months) features described above persist but should decrease in intensity and frequency

- Increased avoidance behaviour

- Irritability is often most persistent

- Substance misuse is common for managing arousal should not be underestimated, and clinicians might need to remind families of this. Recovery is the norm but may be delayed where there is further stress.

Acute stress disorder is a relatively new diagnosis which involves a shorter timescale and the presence of dissociative symptoms (Table 1). Studies of survivors of motor vehicle accidents have found rates of acute stress disorder ranging from about $13 \%$ (Harvey \& Bryant, 1998) to 21\% (Holeva et al, 2001). Higher rates are found for victims of violence (Classen et al, 1998; Elklit, 2002).

\section{Acute stress disorder and PTSD}

According to DSM-IV, an individual's diagnosis changes from acute stress disorder to acute PTSD if symptoms persist for more than month. After 3 months of symptoms, the diagnosis changes again to chronic PTSD. There is evidence that a diagnosis of acute stress disorder can identify a significant proportion of people with acute trauma who go on to develop PTSD (around 80\%; Harvey \& Bryant, 2000). It has been argued that placing greater emphasis on re-experiencing, avoidance and arousal symptoms can further increase the predictive power of these diagnostic criteria. However, there is considerable

\section{Table 1 DSM-IV criteria for PTSD and acute stress disorder}

\begin{tabular}{|c|c|c|}
\hline Criterion & PTSD & Acute stress disorder \\
\hline Stressor criterion & $\begin{array}{l}\text { Involves objective and subjective criteria: } \\
\text { (a) the person experienced, witnessed or } \\
\text { was confronted with threatening, } \\
\text { serious events } \\
\text { (b) the person's response involved intense } \\
\text { fear, helplessness or horror }\end{array}$ & As for PTSD \\
\hline Dissociative phenomena & None & $\begin{array}{l}\text { At least three of five dissociative } \\
\text { symptoms: emotional numbing/ } \\
\text { detachment, reduced environmental } \\
\text { awareness, derealisation, deperson- } \\
\text { alisation, amnesia }\end{array}$ \\
\hline Intrusive phenomena & $\begin{array}{l}\text { Persistent re-experiencing in at least one of } \\
\text { five ways: e.g. intrusive recollections, dreams, } \\
\text { flashbacks, psychological distress }\end{array}$ & As for PTSD \\
\hline Avoidance phenomena & $\begin{array}{l}\text { At least three of seven ways of avoidance } \\
\text { behaviour: e.g. avoidance of thoughts, feel- } \\
\text { ings or reminders of the trauma, amnesia, } \\
\text { decreased interest, feelings of detachment }\end{array}$ & As for PTSD \\
\hline Hyperarousal phenomena & $\begin{array}{l}\text { At least two of five possible symptoms: } \\
\text { insomnia, irritability, poor concentration, } \\
\text { hypervigilance, exaggerated startle response }\end{array}$ & As for PTSD \\
\hline Duration & At least 1 month & Lasts from 2 days to 4 weeks \\
\hline $\begin{array}{l}\text { Impairment of social } \\
\text { functioning }\end{array}$ & $\begin{array}{l}\text { The symptoms must cause clinically } \\
\text { significant distress or social dysfunction }\end{array}$ & As for PTSD \\
\hline
\end{tabular}


overlap between acute stress disorder and acute PTSD if the duration criteria are removed, and both are equally predictive of later PTSD, bringing into question the need for a separate diagnosis of acute stress disorder (Brewin et al, 2003).

Table 1 outlines the DSM-IV criteria for PTSD. The phrase 'outside the range of usual human experience' has now been dropped from the definition. This is in part the result of research which suggests that the perception of fear and threat is crucial in the genesis of PTSD, so that PTSD is possible after events which are common but terrifying (including road traffic accidents and domestic violence).

\section{Risk factors for PTSD}

Individuals who develop PTSD represent only a subset of those exposed to trauma, suggesting that certain people are at risk for development of the disorder after exposure to trauma whereas others appear to be more resilient. ${ }^{+}$Box 2 shows some of the established risk factors for PTSD (McFarlane, 1996). The magnitude and degree of exposure to the stressor influence the risk of developing PTSD. Gender also appears to be significant, with twice the rates of PTSD in women than in men, despite lower reported exposure. Previous personality traits, coping styles and experiences also influence the development of PTSD. Repressive coping style, indicated by low anxiety and high defensiveness, appears to reduce the likelihood of developing PTSD (Ginzburg et al, 2002). Other risk factors include previous traumatisation (Smith et al, 1990), peri-traumatic dissociative experiences (Birmes et al, 2003) and early sensitisation of the hypothalamic-pituitary-adrenal (HPA) axis (Yehuda, 1999, 2002).

In some people PTSD has an unremitting course: more than one-third have a clinical diagnosis of the disorder many years after the onset of their index episode (Kessler et al, 1995). The majority of patients who do recover from PTSD still report subthreshold symptoms (Ehlers et al, 1998). A number of factors have been identified as important in the maintenance of PTSD, including social support and organisational environment. In addition, being divorced and/or widowed, lower education and lower income, concurrent family stressors and a low level of psychosocial functioning appear to be important in the maintenance of chronic PTSD (Zlotnick et al, 2004).

The development of PTSD is therefore the complex result of the interaction of individual vulnerability and resilience with factors related to the severity

${ }^{\dagger}$ For a discussion of resilience and vulnerability in PTSD see pp. 369-375, this issue.

\section{Box 2 Risk factors for PTSD}

Aspect of trauma

- Duration and magnitude of exposure to stressor

- Stressors are sudden and/or occur with no warning

- There is multiple loss of life, mutilation or grotesque imagery

- Criminal violence, especially sexual

Experience during trauma

- Perceived own life to be at real risk

- Perceived lack of control of events, intense fear and helplessness

- Perception of grotesque imagery, especially of human remains or children

- Witnessing or carrying out atrocities, e.g. murder, torture

- High levels of dissociative symptoms at the time of the event

Characteristics of the individual

- Previous psychiatric illness or neuroticism

- Previous exposure to trauma, especially childhood trauma

- Previous coping style

- Denial of trauma and/or avoidance

- Female gender

- Previous acute stress reaction

Post-trauma

- Denial of trauma by others or dismissal of experience

- Lack of social support

of trauma. A fictitious clinical example makes the point. Five men were involved in an aeroplane crash. Superficially, all were exposed to severe lifethreatening trauma, involving grotesque imagery (a fellow passenger was decapitated and his mutilated remains spread over the crash site). On the basis of the nature of the trauma alone, one might expect all the survivors to develop PTSD. However, 18 months later, only two of the five had failed to make a reasonable recovery after a normal stress response. Only one man developed PTSD. His subjective experience of the trauma was particularly unpleasant. There was also evidence that his personality put him at risk. The other man who failed to recover did not have PTSD but was chronically anxious in a way that severely affected his work performance. Each man's subjective account of the crash was different, making the point that subjective experience interacts with objective severity to influence the development of psychopathology. It is therefore not possible to state that only extremes of trauma 
or individual psychological vulnerability lead to the development of PTSD. The relative contributions of past experience and experience of the traumatic event need to be considered during assessment, and have implications for choice of treatment.

\section{Psychopathology and pathophysiology of PTSD}

One of the principal debates about PTSD relates to whether it is an anxiety disorder or a mood disorder. Other possible diagnostic categories are dissociative disorders or personality disorders. The rationale for the various positions is detailed in Box 3 .

Category definition has implications for treatment. Most treatment for PTSD is currently based on symptoms. The pathophysiology of the disorder remains relatively unclear, with research suggesting the involvement of the HPA axis, central monoamine regulation and endogenous opioids. The higher level of cortisol after a trauma might be protective against PTSD, a finding which may shed light on the observed gender disparity (Lamprecht \& Sack, 2002). Activation of the HPA axis during acute stress is an adaptive response, but prolonged elevated glucocorticoid concentrations might lead to neuronal degeneration in areas with high densities of corticoid receptors such as the hippocampus. This might be responsible for the reduced hippocampal volume found in people with PTSD (Hull, 2002). The underactivity of the HPA axis which is observed after exposure to chronic stress might increase vulnerability when facing future trauma. In addition to the neurophysiological disturbances exhibited by people with PTSD, there is also evidence of cognitive psychopathology: people with PTSD are more sensitive to percepts indicating threat and respond more vigorously to such cues (Cassiday et al, 1992).

Neuroimaging studies have also contributed to our understanding of the neurobiological changes seen in trauma survivors. In addition to reduced hippocampal volumes, there appears to be hyperreactivity of the amygdala and reduced activation in the anterior cingular cortex. These findings might respectively reflect the anxiety symptoms and the reduced extinction of conditioned emotional responses which are observed in people with PTSD (Damsa et al, 2005).

In different individuals PTSD can present with either predominantly fear-based or shame-based psychological reactions, reflecting conscious and unconscious beliefs and attitudes about the self and the world. It is these schemata that are addressed using psychological therapies, whereas the autonomic effects of anxiety and depression are best addressed with medication.

\section{Box 3 Models of psychopathology in PTSD}

Anxiety disorder?

- Fear, anxiety and avoidance behaviour (as with phobias)

- Intrusive phenomena resemble obsessivecompulsive disorder

- Introversion and neuroticism are common personality traits in both PTSD and anxiety

- Some people improve with exposure therapy

Mood disorder?

- Sadness and grief, independent of bereavement

- Comorbidity with depression is very common

- Vegetative symptoms (loss of sleep, appetite, libido) are very similar

- Avoidance, numbing and loss of interest as in mood disorders

Dissociative disorder?

- Flashbacks and amnesia are common

Personality disorder?

- Considerable overlap of symptoms with borderline personality disorder

- Some overlap of symptoms with antisocial personality disorder (antisocial behaviour, irritability)

- Some evidence that trauma can induce personality change

Separate neurophysiological disorder?

- Low monoamine oxidase activity

- Increased excretion of urinary betaendorphin

- Therapeutic response to serotonergic drugs and drugs that affect the locus ceruleus

- Deregulation of hypothalamic-pituitaryadrenal axis resulting in low cortisol levels

\section{Other problems post-trauma}

It cannot be overemphasised that PTSD is not the only problem that survivors of trauma face. 'Pure' PTSD after trauma is comparatively rare and comorbidity is the norm. Full-blown PTSD is also relatively uncommon and partial PTSD (Stein et al, 1997), in which there are fewer than the required number of DSM-IV avoidance phenomena or hyperarousal phenomena, might be more likely, particularly in a chronic form. 


\section{Comorbid Axis I disorders}

Depression is the most common co-diagnosis and might be the most common disorder post-trauma. Other psychiatric illnesses post-trauma include anxiety disorders, such as panic disorder or phobic disorders, and substance misuse. These can all lead to more chronic PTSD if not detected and addressed. In particular, the co-occurrence of substance use and anxiety disorders can dramatically reduce the chances of remission (Jacobsen et al, 2001; Zlotnick et al, 2004). Substance misuse might be the primary presenting problem, masking intrusive symptoms of PTSD.

There is now good evidence that PTSD is common in people with severe mental illness such as schizophrenia. Histories of childhood adversity and adult trauma have been commonly reported in people with psychotic disorders (Bebbington et al, 2004). Studies of traumatic experience in community samples have found similar results, which suggests that many people with Axis I disorders might also have either full-blown PTSD or symptoms of PTSD, both of which will amplify other pathology and increase treatment resistance (Mueser et al, 1998). These studies suggest that psychiatrists should look for history of trauma and possible post-traumatic pathology in people presenting with severe mental illness or who appear to be making a poor recovery from psychotic episodes.

\section{Comorbid Axis II disorders}

Marked changes in personality, in terms of personal interaction with others, might cause more problems than any other disorder post-trauma, especially when this is accompanied by substance misuse or violent behaviour (Southwick \& Giller, 1993). The relationship between personality disorder and PTSD is complicated and the diagnosis of complex PTSD can be seen as an attempt to bring together the dichotomy of Axis I (state) and Axis II (trait) symptoms (McClean \& Gallop, 2003). A history of childhood trauma is common in adults with personality disorder, particularly borderline or paranoid personality disorder, but is by no means universal.

Childhood abuse appears to be a risk factor for PTSD independently of personality disorder and early trauma ( $<12$ years of age) and confers an equal risk of depression (Spataro et al, 2004). Adults with these personality disorders are more likely to develop PTSD, through a combination of increased exposure to adult trauma (paranoid personality disorder only) and psychological and social vulnerability (Golier et al, 2003).

\section{Effects on social systems and support}

As in general psychiatric practice, it is important to consider the influence of the disorder on other areas of a person's life, in relation to its effect on the process of recovery and the prognosis. The symptoms of many of the post-traumatic disorders may be troublesome for families and employers, particularly in the first 6-12 months. Families, friends and employers are usually unfamiliar with the timescale of normal recovery, let alone post-traumatic psychiatric illness. Most people do not realise that normal recovery may take 6 months, or longer if there are further stressors, and they might become impatient with survivors, thinking them difficult or weak. Local social support often reduces as press reports of the trauma diminish, and it may seem to healthcare professionals or family members that the trauma happened a long time ago. However, the pathology of PTSD makes the trauma continually real to the survivor (Horowitz, 1973).

\section{The workplace}

After experiencing trauma a person may be chronically irritable and withdrawn for weeks, in a way which is alien to them and their families. There is good evidence that marital stress and breakdown are increased after traumatic experiences. Work performance may similarly deteriorate because of the person's hypervigilance, accompanying loss of concentration and irritability. However, people often find it impossible to discuss the reasons for this with their employers. Employers may not be sympathetic anyway, especially if the trauma occurred at work (and compensation is being claimed), or where there is a work culture of denial of distress. Examples of this are the emergency or public services, and healthcare professionals. Although the 'macho' culture is changing to some degree, especially within the emergency services, the process is slow, and people may encounter hostility and rejection in their workplace. Compensation claims may not be relevant to the maintenance of PTSD, contrary to popular assumptions of malingering, and the settlement of compensation claims does not appear to influence reported rates of PTSD or return to work following injury (Bryant \& Harvey, 2003).

\section{The home}

Many major personal disasters are never reported in the press. During peacetime, and between major disasters, the principal cause of traumatic stress 
responses is crime, of which the impact on the victim is rarely reported unless it is fatal (Kilpatrick et al, 1989). This applies to both men and women. A good example of this is the plight of the families of murder victims. The killer is often a member of the family and relatives must cope with multiple losses. In one case known to us, a woman presented after her husband murdered their daughter to prevent her from telling the mother about his 20-year affair with a family friend. This woman lost not only her daughter and her husband, she also lost her experience of her marriage and the support of a trusted friend. She was also without funds as the husband had been the principal earner and she did not have access to the bank account. The trial did not take place for a year, and the funeral was delayed several times for post-mortem reports for both defence and prosecution.

These social and legal aspects of post-traumatic dysfunction have a profound influence on the management and prognosis of PTSD, and can cause major setbacks in treatment. A man who becomes homeless because of domestic violence related to his post-traumatic irritability may be unable to cooperate with or tolerate a treatment programme. In-patient treatment might be indicated in such instances. People with PTSD as a result of crime have particular problems: not only may they have reminders of the stressor, such as police identification parades or court appearances, they might be at continued risk of further trauma, such as threats from the defendant.

\section{Assessment}

\section{Ask the question}

It might not always be immediately apparent that the presenting complaint is post-traumatic in origin, and it is important to bear this possibility in mind. Psychiatrists need to be aware that criminal violence is a potent cause of post-traumatic symptoms, and a question about the experience of violent victimisation should now be part of the standard history-taking procedure. This is especially true for people presenting with Axis I disorders, where the experience of victimisation, although not uncommon, might be overlooked (Mueser et al, 1998; Bebbington et al, 2004). We have found that asking people about their most frightening experience to date is a good way to introduce the subject of experienced trauma. Questions such as 'Have you ever been a victim of crime?' or 'Were you abused as a child?' are less productive because the words 'crime' and 'abuse' mean different things to different people.

There is someevidence that healthcare professionals do not ask enough about trauma, although it seems that patients do not resent this (Friedman et al, 1992). People with post-traumatic disorders might find it difficult to describe their experiences and might appreciate a tactful enquiry. In addition, patients may not see their general practitioners (GPs) until some time after traumatic events, so that the importance of an event that might have taken place a year before may be overlooked.

\section{Listen to the answer}

Having enquired about trauma, the assessor must be prepared to hear the patient's account. This entails making enough time for the patient to do this comfortably. If a history of a trauma is already known at referral, then it may be helpful to suggest to patients that history-taking takes place in two stages: a general psychiatric history and an account of the trauma and post-traumatic events. This gives the patients some warning and allows them to prepare themselves, reducing anticipatory anxiety. If the trauma is disclosed during the consultation, and the patient wants to give an account of the experience, then it is important to allow this to take place. People with post-traumatic disorders are very sensitive to the understandable reluctance of others to hear their stories. It might be necessary to let the patient talk for a short time, then negotiate a time for them to return and for the assessment to continue.

It is not advisable to dismiss patients' disclosures of trauma. There is no evidence that patients benefit from being told to 'forget all about it' or 'put it out of your mind'. Intrusive phenomena that cannot be voluntarily excluded are characteristic of PTSD: patients are not actually capable of 'just forgetting'. Dismissal also sends the message that the healthcare professional does not want to hear or does not believe what they are being told. Even when the professional needs to maintain a true scepticism about the patient's account of events (such as in medico-legal work), this does not warrant an unsympathetic manner, which in any case will impede the assessment.

\section{Completing the assessment}

Apart from tactfully and sensitively facilitating the patient's disclosure of their experience of the trauma, psychiatric assessment proceeds along usual lines. Interviews with family members might be invaluable for information on the pre-traumatic state of the patient, and might also give an insight into the course of the post-traumatic sequelae. Discussion with the GP and examination of the GP records may yield more valuable information about the patient's pre-traumatic state, and is essential for medico-legal assessments for PTSD claims. 


\section{Box 4 Key questions in the assessment of post-traumatic disorders}

For the clinician

- When did the trauma occur?

- How long has the person had symptoms?

- How have they coped to date?

- What resources do they have to support them?

- Is there a previous history of trauma?

- Is there a history of psychiatric illness pretrauma?

- Was the trauma risky? (criminal assaults or exposure to grotesque imagery)

For the patient

- What is the most frightening thing that happened to you before this traumatic experience?

- Were you ever frightened of your parents when you were a child?

- Were there any other adults who frightened you when you were a child?

- What was the worst thing about this traumatic experience?

- What is its worst effect on you?

Key questions in the assessment are outlined in Box 4 . If the trauma happened only recently (say in the past 3-6 months) some spontaneous progress may still be made or progress may be augmented with support. Positive signs include the diminishing frequency of nightmares, decreasing use of alcohol and the return of appetite. Spontaneous progress may be retarded by the degree of trauma, simultaneous losses and physical ill health (psychological recovery might not be possible until the physical state of the patient allows it). If they are making progress, then it may be that all they need is pharmacological support for the remaining symptoms, information about the natural course of stress reactions and advice from the GP. The support of community psychiatric nurses may also be useful. Contact details that might be helpful for people with PTSD and their families are given in Box 5.

General practitioners are the obvious professionals to be involved in the management of acute stress reactions. If patients are referred to psychiatric services while still in the acute phase of response:

- the GP might lack information about PTSD and might need consultation with the psychiatrist

- the GP/practice counsellor/psychologist might have particular concerns because of the nature of the symptoms

\section{Box 5 Contact details for helpful agencies}

National Association of Victim Support Schemes 02077359166

Compassionate Friends 08451232304 (help for families after death of a child)

\section{Cruse 08444779400 (help for the bereaved)}

Medical Foundation for the Care of Victims of Torture 02076977777

UK Trauma Group http://www.uktrauma. org.uk (a managed clinical network of UK traumatic stress services)

- the GP or practice team might not have the time to give support

- the nature of the trauma might be particularly serious.

In the early stages, it is useful to consider the risk factors for PTSD and advise both the patient and the GP about these. For example, a man who is the victim of a mugging and who has a history of childhood abuse and previous depression is more at risk of developing PTSD than a man without these risk factors who experiences the same assault. If the trauma is a criminal one, it is important to ascertain the state of any legal proceedings, since this will have an impact on treatment and progress.

People whose traumatic experience took place in the more distant past should be advised that treatment may be less effective. Careful historytaking is necessary to discover why the past trauma seems to be causing distress now, and whether there is a new trauma or a comorbid condition that is relevant here. Patients should also be advised that in the early stages treatment can be psychologically painful and distress may be transiently increased as they reduce avoidance and denial.

\section{Treatment of post-traumatic disorders}

Once a diagnosis of PTSD has been made, treatment should be vigorous because chronic PTSD is hard to treat. Even if the traumatic events took place some time before ( $>1$ year) it might still be worth trying exposure therapy, if the patient can tolerate it. Antidepressant treatment should also be instituted. However, the prognosis after 1-2 years is not good.

Although the natural history of the disorder is for very gradual improvement over time, the concurrent effects on family and work life continually retard 


\section{Box 6 Indicated treatments for post-traumatic} disorders

Acute stress responses

- Debriefing

- Social supports

- Pharmacological supports, e.g. hypnotics

- Information and advice to families

Acute PTSD

- Exposuretherapy maybefirst-linetreatment if intrusive phenomena prominent

- Cognitive therapy

- Brief psychodynamic psychotherapy

- Antidepressants (especially where avoidance prominent)

Chronic PTSD

- Exposure therapy if trauma never discussed

- Cognitive-behavioural approaches may still be effective (group or individual)

- Long-term psychotherapy (group or individual)

- Antidepressants, lithium, carbamazepine

this process. Once chronic PTSD is established, the therapeutic focus may need to be these concurrent problems.

The principal treatment modalities are:

- behavioural and cognitive strategies

- short- and long-term psychological therapies

- medication.

All three may form part of different therapeutic strategies for the same patient over time, depending on the patient's needs. Box 6 shows the range of treatments available, the optimal types of therapy for different disorders and their timing. There is no evidence that single one-off debriefing sessions are helpful for treatment or that they reduce the incidence of PTSD after trauma (National Institute for Clinical Excellence, 2005).

\section{Behavioural and cognitive strategies}

The rationale for behavioural and cognitive treatments is breaking the cycle of intrusion and avoidance described in Horowitz's model of PTSD (Horowitz, 1973). By exposing the patient to their feared memories or their thoughts about the trauma, avoidance is reduced and control over intrusion is introduced. It is likely that exposure to feared memories is an important part of most posttraumatic therapies. Addressing failures in cognitive processing of fear responses has also been shown to be effective in PTSD (Resick \& Schnike, 1992).
Behavioural and cognitive strategies are probably indicated as first-line treatments where there is good psychological health before the traumatic event and when the event itself is discrete.

\section{Psychological therapies}

Shame-based PTSD reactions are likely to be more common after prolonged childhood trauma, and overlap with the concept of complex PTSD (Herman, 1992) and borderline personality pathology. This type of reaction may be better addressed with shame-based therapies that aim to address the traumatised sense of self through the developing narrative and help restore a sense of meaning (Lindy, 1996). Unlike fear-based therapies, in shame-based therapy the relationship between the patient and the therapist is likely to be itself a major part of the therapeutic process. Previous experiences of fear and safety will be relevant to both types of reaction, especially in relation to forming a therapeutic alliance. Therapeutic approaches such as interpersonal and psychodynamic therapy may be helpful here. There is little evidence that exposurebased approaches are helpful, and they may even exacerbate the problem.

Group psychotherapy may be of particular use when the trauma occurs in a group context, such as occupational settings or transport disasters. Therapeutic communities have been used principally with combat veterans (Silver, 1986). Brief group work is possible when the group focuses on a particular task, such as in the critical incident stress debriefing model described by Mitchell (1983). Group work may be of particular use after sexual assaults, when shame and guilt may be reduced by making the experience less individual (Roth et al, 1988).

\section{Medication}

Medication has an important role in the treatment of post-traumatic disorders, both as symptomatic relief and directly addressing pathology. Detailed accounts of the use of various types of medication are given by Davidson (1992) and Stein et al (2000). Antidepressants, especially the serotonergic agents, may be helpful, as may tricyclics because of their hypnotic effects. Medication alone is unlikely to be helpful but may be necessary to enable patients to undertake other types of therapy later, and may enhance the efficacy of psychotherapy.

\section{Choosing a treatment}

There are particular questions relevant to the selection of treatment. 
What is the worst problem at the moment?

If intrusive phenomena are prominent, this may suggest exposure therapy as part of a cognitivebehavioural package. If depression and distress are worst, then regular supportive therapy sessions plus antidepressants may be most effective.

\section{What supports does this person have?}

Many forms of treatment for PTSD are quite stressful. It is therefore important to ensure that the patient will be well supported, and that the family are informed about the nature and process of therapy.

\section{What solutions to stress is the patient adopting} now?

If a patient is misusing alcohol or drugs as a means of managing their PTSD symptoms this needs to be addressed before any specific PTSD treatment can be implemented. Rarely, patients present with acts of self-harm such as overdoses, and these should not be dismissed as 'attention-seeking'.

\section{Efficacy of treatment}

A number of studies have addressed the efficacy of treatment for PTSD, although they have tended to focus on psychological treatment. A thorough review by Robertson et al (2004) concluded that the evidence is particularly strong for interventions based on cognitive and behavioural therapy, although it is less compelling for other modalities such as acute debriefing interventions. Eye movement desensitisation and reprocessing (EMDR) has always been contentious, in part owing to the seemingly magical nature of the technique - the patient focuses on their traumatic memories while tracking a focal point (often the therapist's finger) in horizontal movements. The evidence base is limited and awaits replication by independent research groups (Robertson et al, 2004). It remains unclear whether the initiation of saccadic eye movements is an integral therapeutic component of the technique or if it is better conceptualised as an unorthodox form of exposure therapy (Rogers \& Silver, 2002).

Psychodynamic psychotherapy and hypnotherapy have intuitive appeal but lack the support of an evidence base, perhaps because of inherent difficulties in standardising such treatments for empirical evaluation. Newer structured psychotherapies, such as interpersonal therapy, have theoretical promise and await further evaluation. Dialectical behaviour therapy may be useful for the treatment of complex PTSD when the effects of trauma early in development have led to problems such as dissociation, impulsivity and unstable relationships. However, further clinical trials are needed (Robertson et al, 2004).

Two meta-analyses and a systematic review have included studies using 'psychodynamic methods' (Sherman, 1998; Van Etten \& Taylor, 1998; Bisson \& Andrew, 2007). Psychological therapies appear to be better than psychotropic medication, although both are better than controls. Sherman found significant effects for all psychological therapies, particularly behavioural therapy, but no support for one single rationale for therapy. Although there is no clear evidence to show that any particular class of medication is more effective or better tolerated than any other, the largest trials showing efficacy to date have been with the selective serotonin reuptake inhibitors. There have been negative studies of benzodiazepines and inositol (Stein et al, 2000). There is currently a lack of information about the efficacy of treatment for complex PTSD, which is more common in victims of childhood trauma or chronic interpersonal violence. Given the resemblance of these disorders to borderline personality disorder, there may be some reason for thinking that cognitive approaches to affect and arousal regulation may be most helpful.

\section{Conclusions}

Traumatic events are not uncommon in civilian life. Survivors of traumatic experiences, both large and small scale, are likely to present to general and specialist psychiatric clinics requiring treatment. Proper diagnosis is essential because treatment for some post-traumatic disorders can be very effective and failure to treat may result in crippling morbidity. There is no evidence to suggest that the majority of people who present with post-traumatic psychopathology are fabricating symptoms for the purposes of compensation. Although this view lingers in the minds of some psychiatrists, 40 years of research suggest that there really are post-traumatic disorders which need and respond to treatment.

\section{Declaration of interest}

None.

\section{References}

Adshead, G. (2000) Psychological therapies for post-traumatic stress disorder. British Journal of Psychiatry, 177, 144-148.

American Psychiatric Association (1994) Diagnostic and Statistical Manual of Mental Disorders (4th edn) (DSM-IV). APA.

Bebbington, P. E., Bhugra, D., Brugra, T., et al (2004) Psychosis, victimisation and childhood disadvantage: evidence from the second British National Survey of Psychiatric Morbidity. British Journal of Psychiatry, 185, 220-226.

Birmes, P., Brunet, A., Carreras, D., et al (2003) The predictive power of peritraumatic dissociation and acute stress symptoms for posttraumatic stress symptoms: a three-month prospective study. American Journal of Psychiatry, 160, 1337-1339. 
Bisson, J. \& Andrew, M. (2005) Psychological treatment of post-traumatic stress disorder (PTSD). Cochrane Database of Systematic Reviews, issue 2 (CD003388). Update Software.

Brewin, C. R., Andrews, B. \& Rose, S. (2003) Diagnostic overlap between acute stress disorder and PTSD in victims of violent crime. American Journal of Psychiatry, 160, 783-785.

Bryant, R. A. \& Harvey, A. G. (2003) The influence of litigation on maintenance of posttraumatic stress disorder. Journal of Nervous and Mental Disease, 191, 191-193.

Cassiday, L., McNally, R. \& Zeitlin, S. (1992) Cognitive processing of trauma cues in rape victims. Cognitive Research and Therapy, 16, 283-295.

Classen, C., Koopman, C., Hales, R., et al (1998) Acute stress disorder as a predictor of posttraumatic stress symptoms. American Journal of Psychiatry, 155, 620-624.

Damsa, C., Maris, S. \& Pull, C. (2005) New fields of research in posttraumatic stress disorder: brain imaging. Current Opinion in Psychiatry, 18, 55-64.

Davidson, J. (1992) Drug therapy of post-traumatic stress disorder. British Journal of Psychiatry, 160, 309-314.

Ehlers, A., Mayou, R. \& Bryant, B. (1998) Psychological predictors of chronic posttraumatic stress disorder after motor vehicle accidents. Journal of Abnormal Psychology, 107, 508-519.

Elklit, A. (2002) Acute stress disorder in victims of robbery and victims of assault. Journal of Interpersonal Violence, 17, 872887.

Friedman, L. S., Samet, J. H., Roberts, M. S., et al (1992) Inquiry about victimisation experiences. Archives of Internal Medicine, 152, 1186-1190.

Galea, S., Vlahov, D., Resnick, H., et al (2003) Trends of probable post-traumatic stress disorder in New York City after the September 11 terrorist attacks. American Journal of Epidemiology, 158, 514-524.

Ginzburg, K., Solomon, Z. \& Bleich, A. (2002) Repressive coping style, acute stress disorder, and posttraumatic stress disorder after myocardial infarction. Psychosomatic Medicine, 64, 748757.

Golier, J. A., Yehuda, R., Bierer, L. M., et al (2003) The relationship of borderline personality disorder to posttraumatic stress disorder and traumatic events. American Journal of Psychiatry, 160, 2018-2024.

Green, B. (1993) Identifying survivors at risk. In International Handbook of Traumatic Stress Syndromes (eds J. Wilson \& B. Raphael). Plenum.

Harvey, A. G. \& Bryant, R. A. (1998) The relationship between acute stress disorder and posttraumatic stress disorder: a prospective evaluation of motor vehicle accident survivors. Journal of Consulting and Clinical Psychology, 66, 507-512.

Harvey, A. G. \& Bryant, R. A. (2000) Two-year prospective evaluation of the relationship between acute stress disorder and posttraumatic stress disorder following mild traumatic brain injury. American Journal of Psychiatry, 157, 626-628.

Herman, J. (1992) Complex PTSD: a syndrome in survivors of prolonged and repeated trauma. Journal of Traumatic Stress, 5, 377-391.

Holeva, V., Tarrier, N. \& Wells, A. (2001) Prevalence and predictors of acute stress disorder and PTSD following road traffic accidents: thought control strategies and social support. Behavior Therapy, 32, 65-83.

Horowitz, M. (1973) Phase oriented treatment of stress response syndromes. American Journal of Psychotherapy, 27, 506-515.

Hull, A. M (2002) Neuroimaging findings in post-traumatic stress disorder. Systematic review. British Journal of Psychiatry, 181, 102-110.

Jacobsen, L. K., Southwick, S. M. \& Kosten, T. R. (2001) Substance use disorders in patients with posttraumatic stress disorder: a review of the literature. American Journal of Psychiatry, 158, 1184-1190.

Kessler, R. C., Sonnega, A., Bromet, E., et al (1995) Posttraumatic stress disorder in the National Comorbidity Survey. Archives of General Psychiatry, 52, 1048-1060.

Kilpatrick, D., Saunders, B. E. \& Amick McMullen, A. (1989) Victim and crime factors associated with the development of crime related PTSD. Behavior Therapy, 20, 199-214.

Lamprecht, F. \& Sack, M. (2002) Posttraumatic stress disorder revisited. Psychosomatic Medicine, 64, 222-237.
Lindy, J. (1996) Psychoanalytic psychotherapy of post-traumatic stress disorder: the nature of the therapeutic relationship. In Traumatic Stress: The Effects of Overwhelming Experience on Mind, Body and Society (eds B. van der Kolk, A. McFarlane \& L. Weisaeth), pp. 525-536. Guilford Press.

McFarlane, A. (1996) Resilience, vulnerability and the course of posttraumatic reactions. In Traumatic Stress: The Effects of Overwhelming Experience on Mind, Body and Society (eds B. van der Kolk, A. McFarlane \& L. Weisaeth), pp. 155-170. Guilford Press

McLean, L. M. \& Gallop, R. (2003) Implications of childhood sexual abuse for adult borderline personality disorder and complex posttraumatic stress disorder. American Journal of Psychiatry, 160, 369-371.

Mitchell, J. (1983) When disaster strikes - the critical incident stress debriefing process. Journal of Emergency Medical Services, 8, 36-38.

Mueser, K., Goodman, C. B., Trumbetta, S. L., et al (1998) Trauma and PTSD in severe mental illness. Journal of Consulting and Clinical Psychology, 66, 493-499.

National Institute for Clinical Excellence (2005) The Management of PTSD in Adults and Children in Primary and Secondary Care. NICE.

Perkonigg, A., Kessler, R. C., Storz, S., et al (2000) Traumatic events and post-traumatic stress disorder in the community: prevalence, risk factors and comorbidity. Acta Psychiatrica Scandinavica, 101, 46-59.

Resick, P. \& Schnike, M. (1992) Cognitive processing therapy for sexual assault victims. Journal of Consulting and Clinical Psychology, 60, 748-756.

Robertson, M., Humphreys, L. \& Ray, R. (2004) Psychological treatments for posttraumatic stress disorder: recommendations for the clinician based on a review of the literature. Journal of Psychiatric Practice, 10, 106-118.

Rogers, S. \& Silver, S. M. (2002) Is EMDR an exposure therapy? A review of trauma protocols. Journal of Clinical Psychology, 58, 43-59.

Roth, S., Dye, E. \& Liebowitz, V. (1988) Group therapy for sexual assault victims. Psychotherapy, 25, 82-93.

Sherman, J. J. (1998) Effects of psychotherapeutic treatments for PTSD: a meta-analysis of controlled trials. Journal of Traumatic Stress, 11, 413-436.

Silver, S. M. (1986) An inpatient program for PTSD: context as treatment. In Trauma and its Wake (vol. 2) (ed. C. Figley), pp. 142-152. Brunner-Mazel.

Southwick, S. \& Giller, E. (1993) Personality disorders in treatment seeking combat veterans with PTSD. American Journal of Psychiatry, 150, 1020-1023.

Smith, E., North, C., McCool, R., et al (1990) Acute post-disaster psychiatric disorders: identification of persons at risk. American Journal of Psychiatry, 147, 202-206.

Spataro, J., Mullen, P., Burgess, P. M., et al (2004) Impact of child sexual abuse on mental health: prospective study in males and females. British Journal of Psychiatry, 184, 416-421.

Stein, D. J., Zungu-Dirwayi, N., van Der Linden, G. J., et al (2000) Pharmacotherapy for posttraumatic stress disorder. Cochrane Database of Systematic Reviews, issue 4 (CD002795). Update Software.

Stein, M. B., Walker, J. R., Hazen, A. L., et al (1997) Full and partial post-traumatic stress disorder: findings from a community survey. American Journal of Psychiatry, 154, 1114-1119.

Van Etten, M. L. \& Taylor, S. (1998) Comparative efficacy of treatment for post-traumatic stress disorder: a meta-analysis. Clinical Psychology in Psychotherapy, 5, 126-144.

World Health Organization (1992) The ICD-10 Classification of Mental and Behavioural Disorders: Clinical Descriptions and Diagnostic Guidelines. WHO.

Yehuda, R. (1999) Biological factors associated with susceptibility to posttraumatic stress disorder. Canadian Journal of Psychology, 44, 34-39.

Yehuda, R. (2002) Clinical relevance of biological findings in PTSD. Psychiatric Quarterly, 73, 123-133.

Zlotnick, C., Rodriguez, B. F., Weisberg, R. B., et al (2004) Chronicity in posttraumatic stress disorder and predictors of the course of posttraumatic stress disorder among primary care patients. Journal of Nervous and Mental Disease, 192, 153-159. 


\section{MCQs}

1 The diagnosis of acute stress disorder:

a leads to PTSD in more than half of instances

$\mathrm{b}$ can be made in the absence of dissociative symptoms

c is valid after 1 month

$\mathrm{d}$ is seen in over half of road transport accident survivors

e is easy to distinguish from early PTSD once the time criteria are removed.

2 It is known that:

a men more commonly develop PTSD than women

$\mathrm{b}$ dissociative experiences are protective in the development of PTSD

C previous victimisation is protective in the development of PTSD

d for PTSD to develop, the trauma must be 'outside the range of usual human experience'

e repressive coping style reduces the likelihood of PTSD.

3 When assessing trauma victims:

a it is best to avoid the trauma history if the patient becomes upset

b the nature of the trauma is the most important aspect of the traumatic event

c substance misuse may be the primary presenting problem in PTSD

d elucidation of ongoing compensation claims is vital

$\mathrm{e}$ it is not important to enquire about coping strategies.
4 In the treatment of acute stress disorder and PTSD

a debriefing is effective in preventing the development of PTSD

$\mathrm{b}$ benzodiazepines have a role in managing arousal in PTSD

c fear-based reactions should not be managed with exposure therapies

d shame-based reactions are best managed with relational therapies

e there is no role for psychodynamic therapy in PTSD.

5 It is accepted that:

a complex PTSD is a DSM-IV diagnosis

b complex PTSD represents the interaction between personality and trauma

c childhood trauma is more prevalent in all personality disorders

d PTSD is considered 'chronic' after 2 months

e comorbid depression is the most important factor in maintaining the chronicity of PTSD.

\section{MCQ answers}

$\begin{array}{llllllll}1 & & 2 & & 3 & & 4 & 5 \\ \text { a } & \text { T } & \text { a F } & \text { a F } & \text { a F } & \text { a F } \\ \text { b F } & \text { b F } & \text { b F } & \text { b F } & \text { b T } \\ \text { c F } & \text { c F } & \text { c T } & \text { c F } & \text { c F } \\ \text { d F } & \text { d F } & \text { d F } & \text { d T } & \text { d F } \\ \text { e F } & \text { e T } & \text { e F } & \text { e F } & \text { e F }\end{array}$

